\title{
The use of bupropion SR in cigarette smoking cessation
}

\author{
Scott Wilkes \\ Department of Primary and \\ Community Care, School of Health, \\ Natural and Social Sciences, \\ University of Sunderland, Sunderland, \\ United Kingdom
}

\begin{abstract}
Cigarette smoking remains the largest preventable cause of premature death in developed countries. Until recently nicotine replacement therapy (NRT) has been the only recognised form of treatment for smoking cessation. Bupropion, the first non-nicotine based drug for smoking cessation was licensed in the United States of America (US) in 1997 and in the United Kingdom (UK) in 2000 for smoking cessation in people aged 18 years and over. Bupropion exerts its effect primarily through the inhibition of dopamine reuptake into neuronal synaptic vesicles. It is also a weak noradrenalin reuptake inhibitor and has no effect on the serotonin system. Bupropion has proven efficacy for smoking cessation in a number of clinical trials, helping approximately one in five smokers to stop smoking. Up to a half of patients taking bupropion experience side effects, mainly insomnia and a dry mouth, which are closely linked to the nicotine withdrawal syndrome. Bupropion is rarely associated with seizures however care must be taken when co-prescribing with drugs that can lower seizure threshold. Also, bupropion is a potent enzyme inhibitor and can raise plasma levels of some drugs including antidepressants, antiarrhythmics and antipsychotics. Bupropion has been shown to be a safe and cost effective smoking cessation agent. Despite this, NRT remains the dominant pharmacotherapy to aid smoking cessation.
\end{abstract}

Keywords: bupropion, smoking cessation, nicotine addiction

\section{Introduction}

Approximately one-quarter of adults in the United Kingdom (UK) smoke cigarettes with smoking being the largest single cause of death in the UK. Cigarette smoking is estimated to cost the National Health Service (NHS) approximately $£ 1500$ million per year (RCP 2000). Approximately half of all smokers will die prematurely as a result of smoking cigarettes and in the next 50 years about 450 million deaths worldwide will be attributable to smoking cigarettes (Jha et al 2006).

Until recently UK smokers have had little choice of agent or method when attempting to stop smoking. Prior to June 2000 the only pharmacotherapy available to help smokers quit was nicotine replacement therapy (NRT) prescribed on a private basis. In June 2000, bupropion (amfebutamone), an amphetamine-based drug, was licensed for use in smoking cessation in the UK and general practitioners were able to prescribe it within the NHS. The NHS prescription of NRT followed soon after in April 2001 allowing free prescription to disadvantaged sections of society, who have a higher prevalence of smoking and associated morbidities (Jha et al 2006). These changes were in line with the UK government's drive to address a major cause of morbidity and death in the UK with the publication of "Smoking Kills: A White Paper on Tobacco" (Secretary of State for Health 1998). Bupropion and NRT have continued to complement each other in the UK's smoking cessation strategy (NICE 2002) with bupropion taking a 5\% share of total prescribing for smoking cessation in the UK (Department of Health 2006). Additionally, varenicline, a selective nicotinic receptor partial agonist 
was licensed in the UK in December 2006 and recommended by NICE in July 2007 as an option for smokers who have expressed a desire to stop smoking (NICE 2007).

Bupropion was developed as an antidepressant for the treatment of major depressive disorder in 1989 as a thrice-daily immediate release formulation (Fava 2005). In 1996 a twicedaily sustained release (SR) formulation was produced and, in 1997 the smoking cessation properties were first noticed in the United States of America (US) (Tong et al 2006). Following evaluation as an anti-smoking agent (Hurt et al 1997), it became licensed as an aid to smoking cessation and is now a recognised first line antismoking agent in both the UK and US. However it has not been accepted into all health care systems throughout the world (Bloomfield 2005). An extended release formulation became available in 2003 for the treatment of major depression, but it is the SR formulation that continues to be evaluated for its use in smoking cessation.

Bupropion is licensed for use in patients over the age of 18 years and is available in the SR formulation (GlaxoSmithKline 2006). Patients themselves set a target quit date, typically 2 weeks hence, and are prescribed $150 \mathrm{mg}$ daily for 6 days followed by $150 \mathrm{mg}$ twice daily for 7 to 9 weeks. The first prescription for bupropion should last approximately 4 weeks and take the patient beyond the target quit date. Those who return following successful cessation are given the remainder of the treatment course.

This review considers the cumulative evidence for the mechanism of action of bupropion, the recent evidence for its effectiveness as a smoking cessation agent, its cost effectiveness, its use in different clinical groups, and its safety profile.

\section{Method}

A MEDLINE search was performed to select contemporary articles on bupropion for smoking cessation. The Medical Subject Heading (MeSH) terms 'bupropion' and 'smoking cessation' were applied and restricted to articles written in English. A total of 533 articles relating to the use of bupropion for smoking cessation were included in the review. In addition, the reference lists of articles in the initial search were reviewed for other significant papers to include in the review. No date limits were applied to the papers included from the bibliography search.

\section{Metabolism and mechanism of action}

Bupropion is absorbed by the gut, metabolised extensively within the liver and excreted through the kidneys with a half-life of approximately 21 hours (Jefferson et al 2005). Bupropion is a potent inhibitor of cytochrome p450 2D6 (Hesse et al 2003; Jefferson et al 2005; Kotlyar et al 2005; Wang et al 2006) and reduces the clearance of drugs metabolised by this enzyme. The effects of bupropion are mediated via its metabolites: hydroxybupropion, threohydrobupropion and erythrobupropion (DTB 2000; Warner et al 2005).

Bupropion exerts its main mechanism of action through dopamine and noradrenalin reuptake inhibition with little serotonergic effect (Warner et al 2005). It also attenuates the stimulant effects of nicotine on the nicotinic acetylecholine receptors (Figure 1).

Cigarette smoking results in nicotine absorption into the blood stream and crosses the blood brain barrier. This in turn causes a release of dopamine into the synaptic cleft of the dopaminergic, pleasure-seeking pathways in the brain. Following a lowering of nicotine intake, dopamine reuptake into the axon terminal vesicles occurs. Bupropion is thought to exert its main effect by inhibiting this dopamine reuptake, probably by its influence on the dopamine transporter system (Warner et al 2005). However, bupropion appears to have differing effects on dopamine within different areas of the brain. In the nucleus accumbens, bupropion antagonises dopamine reuptake (Nomikos et al 1992) but has also been shown to increase striatal vesicular transport (Rau et al 2005) thus increasing reuptake from the synaptic cleft here. Dopamine reuptake inhibition in the nucleus accumbens reduces the dopamine deficiency experienced in nicotine withdrawal and may explain the attenuating effect bupropion has on nicotine withdrawal symptoms.

Bupropion is also a weak noradrenalin reuptake inhibitor (Ascher et al 1995). This mechanism of action is credited with its antidepressant effects at higher doses than those used for smoking cessation (Fava et al 2005). Noradrenalin release from the hippocampus has been demonstrated in opiate withdrawal (Done et al 1992). A similar process may occur with other drugs of dependence including nicotine and bupropion has been shown to be of benefit in treating patients who experience amphetamine addiction (Newton et al 2005), cocaine dependence (Poling et al 2006) and generalized addictive behaviors (Dannon et al 2005). The mechanism by which bupropion influences the noradrenergic system is poorly understood and continues to be a subject for investigation.

At the postsynaptic acetylcholine nicotinic receptor, bupropion antagonizes the effect of nicotine (Warner et al 2005) and has been shown to block the pharmacological effects of nicotine in vivo (Slemmer et al 2000). Bupropion 


\section{Schematic diagram of a neuronal synapse}

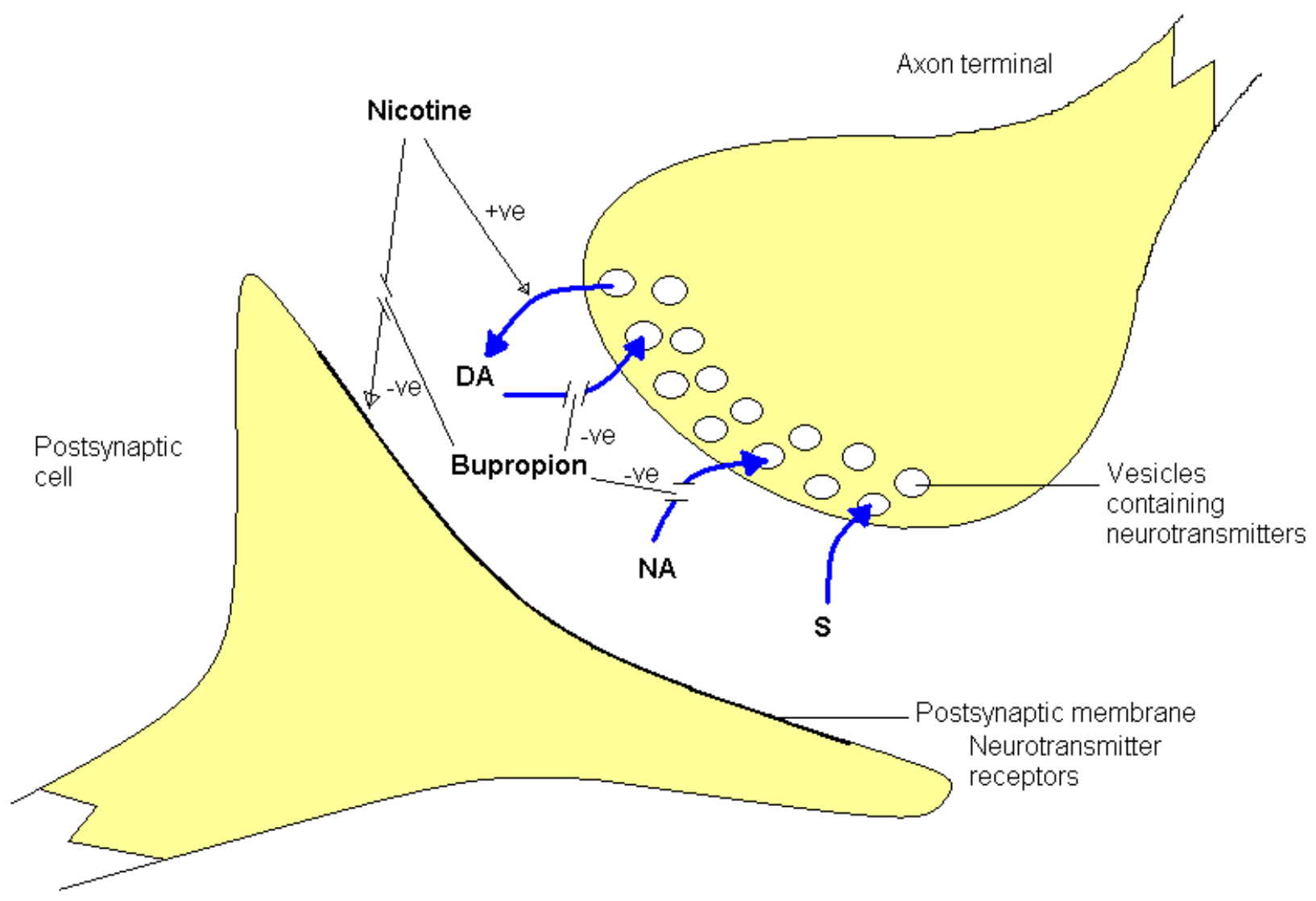

Figure I The effect of bupropion in the synaptic cleft. Dopamine (DA), noradrenalin (NA) and serotonin (S).

may also inhibit nicotine induced vesicular release of dopamine (Miller et al 2002). These effects may explain the ability of bupropion to break the reinforcing effect experienced by chronic nicotine addiction. What is unclear is whether bupropion exerts any longer term effects preventing relapse following cessation of treatment.

\section{Smoking cessation}

Bupropion is licensed for smoking cessation in both the UK and US and is recommended as a first line agent for smoking cessation (NICE 2002). Approximately 1 in 5 smokers successfully stop and remain non-smoking at one year with bupropion therapy (Table 1). The initial landmark trials of Hurt and Jorenby were conducted on healthy non-depressed patients and found comparable significant one-year abstinence rates for bupropion therapy compared with placebo $(23 \%$ vs $12 \%, \mathrm{p}=0.01$, Hurt et al $1997 ; 30 \%$ vs $16 \%$, p < 0.001, Jorenby et al 1999). A recent Cochrane systematic review of 19 randomized trials, showed that bupropion doubled the odds of smoking cessation over placebo (Odds ratio $2.06,95 \%$ confidence intervals 1.77 to 2.40 ; Hughes et al 2004). Highlights of the main double-blind randomized placebo-controlled trials are shown in Table 1.

Sixty percent of patients who attempt to stop smoking have had previous attempts to quit (Wilkes et al 2005). They often require repeated help from health professionals to eventually overcome their addiction (Errard-Lalande 2005) but the motivation that brings smokers back to try again will often lead to eventual success (Boardman et al 2005).

The efficacy of bupropion appears not to diminish with repeated exposure (Rauhut et al 2005). Gonzales showed successful treatment with bupropion in a randomized placebocontrolled trial of 450 patients who had previously failed with bupropion (Gonzales et al 2001). Six month continuous abstinence rates following treatment with bupropion SR $150 \mathrm{mg}$ bd versus placebo were $12 \%$ vs $2 \%, \mathrm{p}<0.001$. Some authors advocate supporting a smoking reduction policy (Hughes et al 2005), although six-month abstinence rates for smokers interested in reducing but not quitting smoking showed non-significant results when compared with placebo 


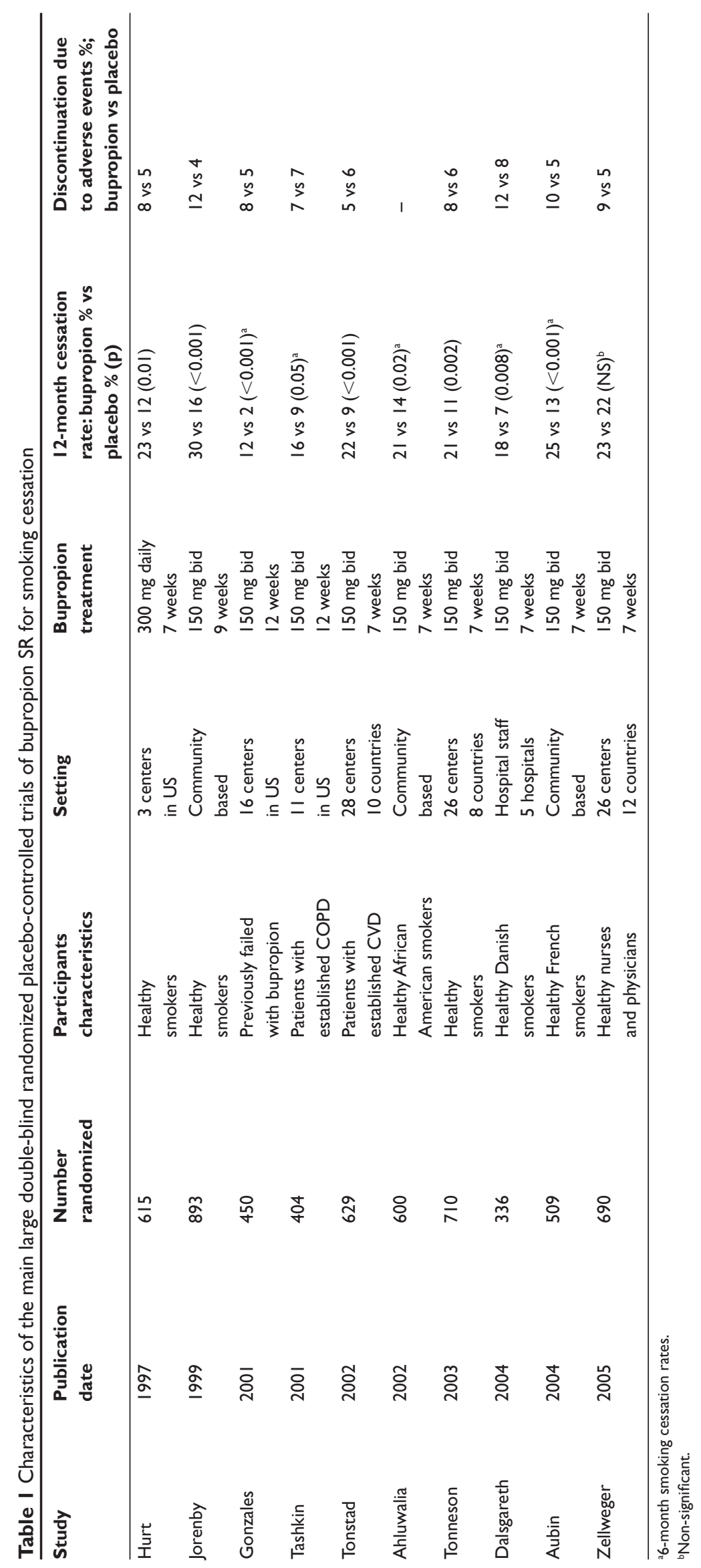


( $7 \%$ vs $5 \%, p=0.5$ : Hatsukami et al 2004). Only one study in Table 1 showed a non-significant difference in one-year smoking cessation rates, but did show a significant continuous abstinence rate at 7 weeks ( $50 \%$ vs 40\%, p = 0.013; Zellweger et al 2005). These authors conclude that bupropion is a successful antismoking agent. Strategies to prevent relapse however following discontinuation of treatment need to be examined. Questions still remain over longer-term success with bupropion for smoking cessation following discontinuation of treatment. Extended treatment of 14 weeks bupropion does not improve one year abstinence rates compared with placebo (33\% vs 34\% NS; Killen et al 2006).

\section{The use of bupropion in disease specific patient groups}

Bupropion has been trialed in healthy smokers, depressed smokers, smokers with cardiovascular disease (CVD) and smokers with chronic obstructive pulmonary disease (COPD). Bupropion, despite being developed as an antidepressant is no more effective in depressed patients compared with non-depressed patients and exerts its smoking cessation effects in ways other than alleviating depressive symptoms (Catley et al 2005). Co-prescribing with antidepressants however can lead to a reduced clearance of some antidepressants through the enzyme inhibitory effects of bupropion. This in turn can potentiate the effect that antidepressants have in lowering seizure threshold for bupropion-induced seizures. In patients with established CVD, bupropion has similar success rates compared with healthy smokers (27\% bupropion vs $11 \%$ placebo at 26 weeks, $22 \%$ vs $9 \%$ at 52 weeks, p $<0.001$; Tonstad et al 2003) and is recommended for this group of patients. The safety, tolerability and efficacy of bupropion for smoking cessation in patients with COPD has also been established with one-year continuous abstinence rates of $16 \%$ for bupropion compared with $9 \%$ for placebo (Tashkin et al 2001). One other trial on patients with COPD has shown modest success at 6 months with abstinence rates of $13 \%$ for bupropion and $10 \%$ for placebo (Wagena et al 2005), however concern has been expressed recently that bupropion may elevate pulmonary pressure in these patients (Paganelli et al 2006). Not all patient groups have demonstrated success with bupropion therapy, which appears to be relatively ineffective in smokers with schizophrenia (Evins et al 2005). Evins et al demonstrated a $16 \%$ abstinence rate at 4 weeks with bupropion compared with $0 \%$ for placebo but the effect did not persist beyond discontinuation of bupropion treatment.

\section{Safety profile}

\section{Adverse effects}

A large post-marketing observational cohort study of 11,735 patients found the most commonly reported adverse events reported were insomnia, nausea/vomiting and dizziness (Boshier et al 2003). There was no evidence of an increase in mortality at 12 weeks post treatment with bupropion. Seizures have been reported to occur at a rate of approximately $0.1 \%$ (GlaxoSmithKline 2006), although in a review of 221 clinical efficacy trials including over 4000 patients, no seizures were reported (Richmond and Zwar 2003).

Adverse effects of bupropion are experienced more often than with NRT though the discontinuation rate is similar between the two therapies. Approximately $9 \%$ of patients using either bupropion or NRT will discontinue treatment and a further $13 \%$ will stop treatment temporarily (Barrueco et al 2005). Adverse effects are experienced by approximately half of those treated in the first two weeks with only $6 \%$ reporting adverse effects by 3 months (Barrueco et al 2005). Pragmatic observational studies have shown between one third and two thirds of patients experience adverse effects with 30\% stopping treatment due to adverse effects (Paluck et al 2006; Wilkes et al 2005). Table 1 shows the treatment discontinuation rates due to adverse events in the major explanatory trials of bupropion.

The main side effects experienced with bupropion are shown in Table 2. Nicotine withdrawal also causes symptoms that are similar to the side effects reported during bupropion therapy. This may partly explain why no significant difference has been demonstrated between

Table 2 Prevalence of side effects of bupropion SR (range \%). Pooled data from trials in Table I

\begin{tabular}{lll}
\hline & Placebo \% & Bupropion \% \\
\hline Insomnia $^{\text {a }}$ & $9-21$ & $24-42$ \\
Headache & $3-33$ & $4-33$ \\
Dry mouth $^{\text {b }}$ & $4-24$ & $6-28$ \\
Rash/Pruritus & 7 & 15 \\
Rhinitis & $12-17$ & $10-14$ \\
Nausea/Vomiting & $5-6$ & $9-13$ \\
Dizziness & $1-6$ & $2-11$ \\
Anxiety & $5-11$ & $5-9$ \\
Flu syndrome & $6-11$ & $4-9$ \\
Taste perversion & 5 & 6 \\
Constipation & 1 & $5-6$ \\
Sweating & 3 & 5 \\
Mood disorder & 4 & 4 \\
\hline
\end{tabular}

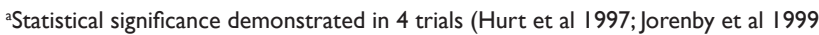
Ahluwalia et al 2002; Dalsgard et al 2004).

'Statistical significance demonstrated in 2 trials (Hurt et al 1997; Jorenby et al 1999). 
bupropion and placebo for most of the adverse effects in the trials. This theory was supported in the study by Hurt, where the prevalence of reported side effects was similar between both the low and high dose bupropion groups (Hurt et al 1997). A lower dose of bupropion may not be sufficient to produce side effects nor to alleviate withdrawal symptoms. Varenicline has a similar side effect profile to bupropion.

Other side effects of bupropion include tremor, gastrointestinal disturbance, impaired concentration, depression, chest pain, asthenia, tachycardia, hypertension, flushing, confusion, anorexia, tinnitus, visual disturbance, palpitations, hallucinations, abnormal dreams, parasthaesia, irritability, incoordination, urinary retention, urinary frequency, Stevens Johnson syndrome, blood glucose disturbance, and exacerbation of psoriasis (GlaxoSmithKline 2006). A rarer reported side effect was subacute cutaneous lupus erythematosis (Cassis et al 2005).

\section{Contraindications}

Bupropion is contraindicated in patients with a history of seizure, bipolar affective disorder, eating disorders, pregnancy and breast feeding (GlaxoSmithKline 2006). Care must be taken when prescribing for elderly patients, those with liver or renal impairment and when co-prescribing with drugs that cause lowering of seizure threshold. Drugs that lower seizure threshold include antidepressants, antipsychotics, systemic corticosteroids, theophylline and tramadol. Patients who abuse alcohol or have sustained a head injury are also at risk of bupropion-induced seizure.

\section{Drug interactions}

Bupropion is a cytochrome p450 2D6 inhibitor (Kotlyar et al 2005; Jefferson et al 2005) and has the effect of reducing the clearance of drugs metabolized by this enzyme (Wang et al 2006). Drugs metabolized by cytochrome p450 2D6 include SSRIs, tricyclic antidepressants, beta blockers, propafenone, flecanide, risperidone and thioridazine (GlaxoSmithKline 2006; DTB 2000). Co-prescribing bupropion with these drugs should be avoided.

\section{The dangers of bupropion}

Some authors have suggested that bupropion should not be used in pregnancy because of the higher frequency of cardiac malformations observed in a registry of pregnancies exposed to bupropion (Anon 2005). It has been shown to be cardiotoxic in overdose and should be considered as a cause in patients with unexplained widening of the QRS complex in the electrocardiograph (Curry et al 2005). Also there has been one reported case of myocardial infarction in an adolescent taking bupropion, erythromycin, and methylphenidate (George et al 2005). Bupropion is more notably associated with risk of seizures. When prescribed to individuals without a past history of seizure or risk factor for their occurrence, this risk has recently been calculated at approximately 1 in 6000 for first time users of bupropion (Hubbard et al 2005). In overdose this risk doubles (Shepherd 2005). Other adverse effects of bupropion in overdose include dizziness, tremor, nausea and/or vomiting, drowsiness, tachycardia and hallucination (Shepherd 2005).

\section{Economics}

Bupropion is a cost effective treatment for smoking cessation (Ross et al 2005). A systematic review of the clinical and cost effectiveness of bupropion concluded that bupropion was superior to NRT, giving an incremental cost per quality adjusted life year gained (QALY) for bupropion of approximately one third less than that for NRT (Woolacott et al 2002). Using the Global Health Outcomes simulation model with 20 years follow up of 1.3 million men and women in the Swedish population, bupropion and NRT were compared concluding that bupropion was more cost saving than NRT (Bolin et al 2006). The incremental cost per QALY for bupropion was approximately 725 Euro for men and 535 Euro for women (at 2001 prices).

NRT and bupropion are effective aids for smoking cessation and are considered first line agents (Corelli et al 2006). Bupropion however has met opposition when being introduced into some countries. There has been opposition to its introduction in New Zealand where PHARMAC, a body responsible for funding health service treatments, supports the prescribing of cheaper and effective alternatives such as clonidine and nortriptyline (Bloomfield 2005). Nortriptyline and bupropion have been shown to be equally effective for smoking cessation (Hall et al 2005) but interestingly clonidine and nortriptyline are not licensed for smoking cessation in many western countries (Corelli et al 2006).

Despite the clinical and cost effectiveness of bupropion being established, of the $£ 100$ million invested in smoking cessation services in the NHS in the past 12 months only $5 \%$ was spent on bupropion with $82 \%$ being consumed by NRT (Department of Health 2006).

\section{Discussion}

Bupropion is licensed as a first line pharmacotherapy for smoking cessation in both the UK and US. Bupropion is 
effective in the early stages of smoking cessation withdrawal by attenuating the effects of nicotine withdrawal. This is most probably mediated by the inhibition of dopamine reuptake within the synaptic cleft. Craving may also be attenuated by the negative effect bupropion has on the nicotinic acetylcholine receptors in damping the stimulant effect of nicotine on the postsynaptic membrane. What is unclear is whether bupropion has any effect, either on the withdrawal or craving effects of cigarette smoking, following the withdrawal of bupropion treatment. Most of the large trials suggest that a positive benefit with bupropion therapy may be sustained up to one year, but the early success demonstrated by Zellwegger et al (2005) was not sustained following withdrawal of treatment. This supports the theory that bupropion does not modify neurotransmitter activity and has no longer-term effects beyond the treatment period.

Anti-smoking treatments may be more successful if they are tailored to the individuals' genetic susceptibility (Lerman et al 2006). Smokers carrying the dopamine DRD2-141C Ins/Del genotype were examined in an open-labelled randomized trial and those carrying the Ins $\mathrm{C}$ allele were significantly more likely to succeed with bupropion therapy while those with the Del C allele were more successful with NRT (Lerman et al 2006). To date, there has been no evidence to suggest that gender may influence the success or failure of bupropion therapy (Scharf and Shiffman 2004).

None of the clinical trials has shown significant weight gain among patients undergoing bupropion therapy, an important factor to consider as many patients are concerned about weight gain when stopping smoking (Clark et al 2005).

Primary health care physicians including general practitioners and specially trained practice nurses are the best placed professionals to deliver smoking cessation services. Nurses within the NHS have been able to prescribe NRT for a number of year under the Extended Formulary for Nurse Prescribers scheme. From the 1st May 2006 Nurse Independent Prescribing legislation allows UK nurses to prescribe 'any licensed medicine for any medical condition within their professional competencies'. Hence, bupropion and other pharmacological agents for smoking cessation can be prescribed by UK Smoking Cessation Specialist nurses (Department of Health 2007). The slow uptake of nurse prescribing, the British National Formulary recommendation of NRT as the first line therapy for nicotine addiction and the belief that bupropion is not as safe as NRT (Vogt 2006) may in part explain the low uptake of bupropion for smoking cessation. NHS patients who do not have access to these services within the primary care setting are referred to specialist smoking cessation clinics (West et al 2000; NICE 2002). Dentists, who see the direct effects of smoking with nicotine staining of teeth and gingival disease, should also be involved with smoking cessation services (Covington et al 2005). Bupropion therapy, delivered by dental practitioners, is equally effective when compared to general practitioners prescribing of bupropion (Nasry et al 2006) and this role of the dental practitioners has some support (Davis 2005; Pizzo et al 2006).

The smoker craves nicotine in an attempt to produce dopamine overflow in the pleasure seeking areas of the brain. The reinforcing effects of nicotine thus drive the smoker in a quest for steady state neurotransmitter activity within the synaptic cleft. Bupropion therapy delivers this steady state, as does NRT, but at some time the smoker will cease treatment and neurotransmitter activity returns to the pre-smoking state. Whichever route the smoker takes in an attempt to give up smoking he/she will have to go through withdrawal at some stage, whether it is from nicotine in cigarettes, nicotine in NRT or bupropion therapy. Ultimately the smoker craves the steady state of neurotransmitter activity enjoyed by the non-smoker and it is the withdrawal symptoms experienced during the transition back to that steady state that smoking cessation therapies aim to alleviate.

\section{Conclusion}

Bupropion is an effective pharmacotherapy to aid smoking cessation (Ludvig et al 2005; Ross et al 2005) and should be considered as a first line agent along with NRT alone or in combination (Mansourati et al 2005). Both pragmatic observational trials and explanatory randomized trials of bupropion therapy have shown approximately 1 in 5 smokers will successfully remain abstinent from smoking at one year (Hurt et al 1997; Jorenby et al 1999; Tonnesen et al 2003; Tonstad et al 2003; Zellweger et al 2005; Wilkes et al 2005; Paluck et al 2006). Varenicline is also considered as a first line pharmacotherapy for motivated smokers expressing a desire to stop smoking (Frishman 2007; NICE 2007; Nides et al 2007). Varenicline's initial higher quit rate compared to bupropion tails off to similar rates between the two drugs at one year (Gonzales et al 2006; Jorenby et al 2006; Oncken et al 2006; Tonstad et al 2006). Nortriptyline and clonidine have proven efficacy for smoking cessation and are considered as second line agents for smoking cessation (McRobbie et al 2005). There is no evidence to support prolonged bupropion therapy beyond its current license of 7 to 9 weeks and any decision to limit re-treatment is purely a pragmatic one 
(Killen et al 2006). NICE recommend re-treatment after a period of six months (NICE 2002). Also there is only limited evidence that bupropion therapy has a modifying effect upon withdrawal and craving following cessation of treatment (Warner et al 2005).

The next steps in smoking cessation strategies for many countries are the introduction of smoking bans in public places. Bupropion, varenicline and NRT will however continue to play a significant part in helping smokers to quit. Pharmacotherapies alone will not confer successful smoking cessation; psychological support and personal motivation as well as modifying environmental factors are paramount to successful smoking cessation.

\section{Acknowledgments}

Thank you to Dr Paul Creighton, Coquet Medical Group, for help with the preparation of the manuscript and Sally Black and Margaret Creighton with proof reading.

\section{Conflicts of interest}

None declared.

\section{References}

Ahluwalia JS, Harris KJ, Catley D, et al. 2002. Sustained-Release Bupropion for Smoking Cessation in African Americans. JAMA, 288:468-74.

Anon 2005. Bupropion (amfebutamone): caution during pregnancy. Prescrire International, 14:225.

Ascher JA, Cole JO, Colin JN, et al. 1995. Bupropion: a review of its mechanism of antidepressant activity. Journal of Clinical Psychiatry, 56:395-401.

Aubin HJ, Lebargy F, Berlin I, et al. 2004. Efficacy of bupropion and predictors of successful outcome in a sample of French smokers: a randomized placebo-controlled trial. Addiction, 99:1206-18.

Barrueco M, Otero MJ, Palomo L, et al. 2005. Adverse effects of pharmacological therapy for nicotine addiction in smokers following a smoking cessation program. Nicotine and Tobacco Research 7:335-42.

Bloomfield A. 2005. Buproprion, public funding, and smoking cessation. New Zealand Medical Journal, 118:U1576.

Boardman T, Catley D, Mayo MS, et al. 2005. Self-efficacy and motivation to quit during participation in a smoking cessation program. International Journal of Behavioral Medicine, 12:266-72.

Bolin K, Lindgren B, Willers S, et al. 2006. The cost utility of bupropion in smoking cessation health programs: simulation model results for Sweden. Chest, 129:651-60.

Boshier A, Wilton LV, Shakir SA. 2003. Evaluation of the safety of bupropion (Zyban) for smoking cessation from experience gained in general practice use in England in 2000. European Journal of Clinical Pharmacology, 59:767-73.

Cassis TB, Callen JP, Cassis TB, et al. 2005. Bupropion-induced subacute cutaneous lupus erythematosus. Australasian Journal of Dermatology, 46:266-9.

Catley D, Harris KJ, Okuyemi KS, et al. 2005. The influence of depressive symptoms on smoking cessation among African Americans in a randomized trial of bupropion. Nicotine and Tobacco Research, 7:859-70.

Clark MM, Hurt RD, Croghan IT, et al. 2005. The prevalence of weight concerns in a smoking abstinence clinical trial. Addictive Behaviours, 31:1144-52.
Corelli RL, Hudmon KS, Corelli RL, et al. 2006. Pharmacologic interventions for smoking cessation. Critical Care Nursing Clinics of North America, 18:39-51.

Covington LL, Breault LG, O'Brien JJ, et al. 2005. An innovative tobacco use cessation program for military dental clinics. Journal of Contemporary Dental Practice, 6:151-63.

Curry SC, Kashani JS, LoVecchio F, et al. 2005. Intraventricular conduction delay after bupropion overdose. Journal of Emergency Medicine, 29:299-305.

Dalsgard OJ, Hansen NCG, Soes-Petersen U, et al. 2004. A multicenter, randomised, double-blind, placebo-controlled, 6-month trial of bupropion hydrochloride sustained-release tablets as an aid to smoking cessation in hospital employees. Nicotine and Tobacco Research, 6:55-61.

Dannon PN, Lowengrub K, Musin E, et al. 2005. Sustained-release bupropion versus naltrexone in the treatment of pathological gambling: a preliminary blind-rater study. Journal of Clinical Psychopharmacology, 25:593-6.

Davis JM. 2005. Tobacco cessation for the dental team: a practical guide part II: evidence-based interventions. Journal of Contemporary Dental Practice, 6:178-86.

Department of Health. Statistics on NHS Stop Smoking services in England, April 2005 to March 2006. Accessed 24 August 2006.URL: http://www. ic/nhs/pubs/nhsstopsmoking stats2005to2006q4.

Department of health. Nurse independent prescribing. Accessed 14th September 2007. URL: http://www.dh.gov.uk/en/Policyandguidance/ Medicinespharmacyandindustry/Prescriptions/TheNon-MedicalPrescribingProgramme/Nurseprescribing/index.htm

Done C, Silverstone P and Sharp T. 1992. Effect of naloxone precipitated morphine withdrawal on noradrenaline release in rat hippocampus in vivo. Eur J Pharmacol, 215:333-6.

DTB 2000. Bupropion to aid smoking cessation. Drug and Therapeutics Bulletin, 38:73-5.

Errard-Lalande G. 2005. Assisting smoking cessation. Revue des Maladies Respiratoires, 22:8S15-26.

Evins AE, Cather C, Deckersbach T, et al. 2005. A double-blind placebocontrolled trial of bupropion sustained-release for smoking cessation in schizophrenia. Journal of Clinical Psychopharmacology, 25:218-25.

Fava M, Rush AJ, Thase ME, et al. 2005. 15 Years of Experience With Bupropion HCL:From Bupropion to Bupropion SR to Bupropion XL. Primary Care Companion Journal Clinical Psychiatry, 7:106-13.

Frishman WH. 2007. Smoking cessation pharmacotherapy - nicotine and non-nicotine preparations. Preventive Cardiology, 10:10-22.

George AK, Kunwar AR, Awasthi A, et al. 2005. Acute myocardial infarction in a young male on methylphenidate, bupropion, and erythromycin. Journal of Child and Adolescent Psychopharmacology, 15:693-5.

GlaxoSmithKline. 2006. Zyban (bupropion hydrochloride) Sustained Release Tablets. Product Information. Accessed 4 August 2006. URL: http://us.gsk.com/product/assets/us_zyban.pdf.

Gonzales DH, Nides MA, Ferry LH, et al. 2001. Bupropion SR as an aid to smoking cessation in smokers treated previously with bupropion: a randomized placebo-controlled study. Clinical Pharmacology and Therapeutics, 69:438-44.

Gonzales D, Rennard SI, Nides M, et al. 2006. Varenicline, an alpha4beta2 nicotinic acetylcholine receptor partial agonist, vs sustained-release bupropion and placebo for smoking cessation: a randomized controlled trial. JAMA, 296:47-55.

Hall SM, Lightwood JM, Humfleet GL, et al. 2005. Cost-effectiveness of bupropion, nortriptyline, and psychological intervention in smoking cessation. Journal of Behavioral Health Services and Research, 32:381-92.

Hatsukami DK, Rennard S, Patel MK, et al. 2004. Effects of sustainedrelease bupropion among persons interested in reducing but not quitting smoking. American Journal of Medicine, 116:151-7.

Hesse LM, Sakai Y, Vishnuvardhan D, et al. 2003. Effect of bupropion on CYP2B6 and CYP3A4 catalytic activity, immunoreactive protein and mRNA levels in primary human hepatocytes: comparison with rifampicin. Journal of Pharmacy and Pharmacology, 55:1229-39. 
Hubbard R, Lewis S, West J, et al. 2005. Bupropion and the risk of sudden death: a self-controlled case-series analysis using The Health Improvement Network. Thorax, 60:848-50.

Hughes J, Stead L, Lancaster T. 2004. Antidepressants for smoking cessation. Cochrane Database of Systematic Reviews, CD000031.

Hughes JR, Carpenter MJ. 2005. The feasibility of smoking reduction: an update. Addiction, 100:1074-89.

Hurt RD, Sachs DP, Glover ED, et al. 1997. A comparison of sustainedrelease bupropion and placebo for smoking cessation. New England Journal of Medicine, 337:1195-202.

Jefferson JW, Pradko JF, Muir KT, et al. 2005. Bupropion for major depressive disorder: Pharmacokinetic and formulation considerations. Clinical Therapeutics 27:1685-95.

Jha P, Peto R, Zatonski W, et al. 2006. Social inequalities in male mortality, and in male mortality from smoking: indirect estimation from national death rates in England and Wales, Poland, and North America. Lancet, 368:367-70.

Jorenby DE, Leischow SJ, Nides MA, et al. 1999. A controlled trial of sustained-release bupropion, a nicotine patch, or both for smoking cessation. New England Journal of Medicine, 340:685-91.

Jorenby DE, Hays JT, Rigotti NA, et al. 2006. Efficacy of varenicline, an alpha2beta4 nicotinic acetylecholine receptor partial agonist, vs placebo or sustained-release bupropion for smoking cessation: a randomized trial. JAMA, 296:56-63.

Killen JD, Fortmann SP, Murphy GM, et al. 2006. Extended treatment with bupropion SR for cigarette smoking cessation. Journal of Consulting and Clinical Psychology, 74:286-94.

Kotlyar M, Brauer LH, Tracy TS, et al. 2005. Inhibition of CYP2D6 activity by bupropion. Journal of Clinical Psychopharmacology, 25:226-9.

Lerman C, Jepson C, Wileyto EP, et al. 2006. Role of functional genetic variation in the dopamine $\mathrm{D} 2$ receptor (DRD2) in response to bupropion and nicotine replacement therapy for tobacco dependence: results of two randomized clinical trials. Neuropsychopharmacology, 31:231-42.

Ludvig J, Miner B, Eisenberg MJ. 2005. Smoking cessation in patients with coronary artery disease. American Heart Journal, 149:565-72.

Mansourati J, Borel ML, Munier S, et al. 2005. Medications in smoking cessation. Presse Medicale, 34:1331-6.

McRobbie H, Lee M, Juniper Z. 2005. Non-nicotine pharmacotherapies for smoking cessation. Respiratory Medicine, 99:1203-12.

Miller DK, Sumithran SP, Dwoskin LP. 2002. Bupropion inhibits [(3)H] overflow from rat striatal slices preloaded with [(3)] dopamine and from rat hippocampal slices preloaded with [(3)] norepinephrine. J Pharmacol Exp Ther, 302:1113-22.

Nasry HA, Preshaw PM, Stacey F, et al. 2006. Smoking cessation advice for patients with chronic periodontitis. British Dental Journal, 200:272-5.

[NICE] National Institute for Clinical Excellence. 2002. Guidance on the use of nicotine replacement therapy (NRT) and bupropion for smoking cessation. 39. NICE.

[NICE] National Institute for Health and Clinical Excellence. 2007. Varenicline for smoking cessation. 123. NICE.

Newton TF, Roache JD, De La GR, et al. 2005. Safety of intravenous methamphetamine administration during treatment with bupropion Psychopharmacology, 182:426-35.

Nides M, Leischow S, Sarna L, et al. 2007. Maximizing smoking cessation in clinical practice: pharmacological and behavioural interventions. Preventive Cardiology, 10:23-30.

Nomikos GG, Damsma G, Wenkstern D, et al. 1992. Effects of chronic bupropion on interstitial concentrations of dopamine in rat nucleus accumbens and striatum. Neuropsychopharmacology, 7:7-14.

Onken C, Gonzales D, Nides M, et al. 2006. Efficacy and safety of the novel selective nicotinic acetylcholine receptor partial agonist, varenicline, for smoking cessation. Arch Intern Med, 166:1572-7.

Paganelli MO, Tanus-Santos JE, Sabha M, et al. 2006. Hemodynamic effects of bupropion in anesthetized dogs. European Journal of Pharmacology, $530: 124-7$
Paluck EC, McCormack JP, Ensom MH, et al. 2006. Outcomes of bupropion therapy for smoking cessation during routine clinical use. Annals of Pharmacotherapy, 40:185-90.

Pizzo G, Piscopo MR, Pizzo I, et al. 2006. Smoking cessation counselling and dental team. Annali di Igiene, 18:155-70.

Poling J, Oliveto A, Petry N, et al. 2006. Six-month trial of bupropion with contingency management for cocaine dependence in a methadonemaintained population. Archives of General Psychiatry, 63:219-28.

Rau KS, Birdsall E, Hanson JE, et al. 2005. Bupropion increases striatal vesicular monoamine transport. Neuropharmacology, 49:820-30.

Rauhut AS, Dwoskin L, Bardo MT. 2005. Tolerance does not develop to the decrease in nicotine self-administration produced by repeated bupropion administration. Nicotine and Tobacco Research, 7:901-7.

[RCP] Royal College of Physicians of London. 2000. A report of the tobacco advisory group of the Royal College of Physicians. London: RCP.

Richmond R, Zwar N. 2003. Review of bupropion for smoking cessation. Drug and Alcohol Review, 22:203-20.

Ross S, Williams D. 2005. Bupropion: risks and benefits. Expert Opinion on Drug Safety, 4:995-1003.

Scharf D, Shiffman S. 2004. Are there gender differences in smoking cessation, with and without bupropion? Pooled and meta-analyses of clinical trials of Bupropion SR. Addiction, 99:1462-9.

Secretary of State for Health. 1998. Smoking kills: a white paper on tobacco. London: The Stationary Office.

Shepherd G. 2005. Adverse effects associated with extra doses of bupropion. Pharmacotherapy, 25:1378-82.

Slemmer JE, Martin BR, Damaj MI. 2000. Bupropion is a nicotinic antagonist. J Pharmacol Exp Ther, 295:321-7.

Tashkin D, Kanner R, Bailey W, et al. 2001. Smoking cessation in patients with chronic obstructive pulmonary disease: a double-blind, placebocontrolled, randomised trial. Lancet, 357:1571-5.

Tong EK, Carmody TP, Simon JA. 2006. Bupropion for smoking cessation. A Review. Comprehensive Therapy, 32:26-33.

Tonnesen P, Tonstad S, Hjalmarson A, et al. 2003. A multicentre, randomized, double-blind, placebo-controlled, 1-year study of bupropion SR for smoking cessation. Journal of Internal Medicine, 254:184-92.

Tonstad S, Farsang C, Klaene G, et al. 2003. Bupropion SR for smoking cessation in smokers with cardiovascular disease: a multicentre, randomised study. European Heart Journal, 24:946-55.

Tonstad S, Tonnesen P Hajek P, et al. 2006. Effect of maintenance therapy with varenicline on smoking cessation: a randomized controlled trial. JAMA, 296:56-63.

Vogt F, Hall S, Martineau TM. 2006. General practitioners' beliefs about effectiveness and intentions to prescribe smoking cessation medications: qualitative and quantitative studies. BMC Public Health, 6:227.

Wagena EJ, Knipschild PG, Huibers MJ, et al. 2005. Efficacy of bupropion and nortriptyline for smoking cessation among people at risk for or with chronic obstructive pulmonary disease. Archives of Internal Medicine, 165:2286-92.

Wang JS, DeVane CL, Gibson BB, et al. 2006. Population pharmacokinetic analysis of drug-drug interactions among risperidone, bupropion, and sertraline in CF1 mice. Psychopharmacology, 183:490-9.

Warner C, Shoaib M. 2005. How does bupropion work as a smoking cessation aid? Addiction Biology, 10:219-31.

West R, McNeill A, Raw M. 2000. Smoking cessation guidelines for health professionals:an update. Thorax, 55:987-99.

Wilkes S, Evans A, Henderson M, et al. 2005. Pragmatic, observational study of bupropion treatment for smoking cessation in general practice. Postgraduate Medical Journal, 81:719-22.

Woolacott NF, Jones L, Forbes CA, et al. 2002. The clinical effectiveness and cost-effectiveness of bupropion and nicotine replacement therapy for smoking cessation: a systematic review and economic evaluation. Health Technology Assessment (Winchester, England), 6:1-245.

Zellweger JP, Boelcskei PL, Carrozzi L, et al. 2005. Bupropion SR vs placebo for smoking cessation in health care professionals. American Journal of Health Behavior, 29:240-9. 
